\title{
Global Trends of Green Pesticide Research from 1994 to 2019: A Bibliometric Analysis
}

\author{
Hein Hendrik Smith, Oladayo Amed Idris $\mathbb{D}$, and Mark Steve Maboeta $\mathbb{D}$ \\ Unit for Environmental Sciences and Management (UESM), Faculty of Natural and Agricultural Sciences, \\ North-West University, Potchefstroom, North-West, South Africa \\ Correspondence should be addressed to Mark Steve Maboeta; mark.maboeta@nwu.ac.za
}

Received 6 December 2020; Revised 9 February 2021; Accepted 2 March 2021; Published 20 March 2021

Academic Editor: Zongming Ren

Copyright (c) 2021 Hein Hendrik Smith et al. This is an open access article distributed under the Creative Commons Attribution License, which permits unrestricted use, distribution, and reproduction in any medium, provided the original work is properly cited.

\begin{abstract}
The fast-growing world population places food production under enormous pressure to ensure food security. One of the most common methods to increase food production is the use of pesticides, but the continuous use thereof has numerous detrimental effects on the environment. The interest in biopesticides for a possible substitute has grown over the past two decades. To determine the research evolution of biopesticides (green pesticides), a bibliometric analysis from 1994 to 2019 was carried out. A total of 580 documents were found eligible in the Scopus database for this analysis. Parameters such as the number of articles, article citations, keywords, source impact, and countries of publication were used to analyse the documents and rank countries based on authors, productivity, article citations, and co-authorship. The analysis reveals production increased significantly from 2009 and has the most published documents in 2019 with a total of 74 articles. Asia's most populous countries, India and China, were ranked first and second, respectively, and the USA third in terms of the most productive countries in the field of plant biopesticides. Countries in Europe and Africa however have fewer publications than expected in this field, given the fact that they are high consumers of pesticides. India, China, and the USA have $4.08 \%, 2.94 \%$, and $12.5 \%$ multiple country publications (MCPs), respectively, with the USA having a stronger collaboration. Finally, there is a clear indication in this study that India and China are taking the lead in substituting synthetic pesticides with the alternative natural plant biopesticide.
\end{abstract}

\section{Introduction}

The detrimental effects of synthetic pesticides on the environment are well established as it affects animal and plant biodiversity as well as terrestrial and aquatic ecosystems [1]. Other effects include toxicity, soil and groundwater pollution, and harmful residues that contaminate crops and food. It also affects non-target organisms and the excessive use of synthetic pesticides leads to increased resistance in pests [2]. The negative effects of synthetic pesticides have created the need for a safer and more environmentally friendly substitute. Biopesticides are believed to be less toxic, environmentally friendly, and not harmful to humans and nontarget organisms [2]. The use of botanical insecticides is not a new practice. As early as the 17 th century, botanical insecticides have been used in agricultural practices by ancient
China, Egypt, Greece, and India [3]. Over the past decade, the interest in biopesticides has grown immensely, with the intention to substitute with synthetic pesticides. According to a study done by Isman and Grieneisen [4], the number of annual papers published on botanical insecticides has grown from 61 papers in 1980 to 1207 papers in 2012 [4]. This signifies an increase in the awareness and uses of plant biopesticides. In spite of the growing need for natural pest management, plant biopesticides contribute less than $1 \%$ of the total use of pesticides [2]. The annual amount of synthetic pesticides used for crop protection is estimated at 2.5 million tons causing damages worth about $\$ 100$ billion, due to residues in crops, soil and water, nonbiodegradable properties, and high toxicity [5]. Synthetic pesticides are no doubt a threat to public health and demand an urgent alternative with better crop protection and less harmful 
properties. The term "green pesticides" entails all naturally acquired types of pest management from plant extracts, plant-derived pesticides, plant secondary metabolites, and plant-based pesticides [5]. The green pesticides are also referred to as botanical pesticides and are used as repellents, nematicides, insecticides, fungicides, and bactericides, obtained in the form of isolated substances or complex mixtures [6]. Although there has been significant growth in botanical pesticide research, the commercial availability of these pesticides remains limited [7]. According to Isman and Grieneisen [4], there are a few limitations of the exploitation of botanical pesticides such as lack of availability of good quality plant pesticides at affordable prices, strict regulation particularly on endangered plant species, short persistence of the phytochemical in the environment, and the extraction of the phytochemical from plants grown under different climatic conditions resulting in different compositions in terms of active agents, which leads to variability in effectiveness [4]. One of the main factors preventing the advancement of commercializing botanical pesticides is sustainability [6] of the product. In order to produce botanical pesticides on a commercial scale, it is necessary to obtain large amounts of the source plant, which requires large scale production [6]. However, most biopesticide plants are still not grown commercially, making it difficult to source for the plants. Although research on botanical pesticides has increased significantly over the past two decades [8], the above-mentioned limitations still contribute to the lack of commercialization of botanical pesticides.

With the continuously growing interest in botanical pesticides, it is necessary to carry out a bibliometric compilation to better understand the research trend. The fastgrowing number of academic publications makes it extremely difficult to stay up to date with everything being published [9]. To help organise and better understand previous research, different quantitative and qualitative literature reviewing approaches are used. Bibliometrics is one such approach and according to Aria and Cuccurullo [9] it has the potential to perform a "systematic, transparent, and reproducible review process based on the statistical measurement of science, scientists, or scientific activity." Various research fields make use of bibliometrics to measure the impact or influence of certain research articles. For example, in the field of engineering, the authors Bao et al. [10] used bibliometric analysis to evaluate the publications in the field of robotic exoskeletons and the authors He et al. [11] used bibliometrics to analyse articles related to "metastatic castration-resistant prostate cancer" in the field of health and medicine. Muhuri et al. [12] projected the growth structure of the ongoing industrial revolution "Industry 4.0" using bibliometric analysis in the field of intelligent engineering [12]. All these examples mentioned but few indicate bibliometric study is relevant in many fields.

During this study, the objective was to analyse the global research activities on botanical pesticides from 1994 to 2019 , in the Scopus database. The data obtained was then used to study the research progression using bibliometric parameters and indicators such as most productive authors, most productive countries, annual scientific production, country collaboration, average article citations per year, average total citations per year, most relevant keywords, bibliographic coupling, and documents production source impact. The Scopus database was chosen as it includes a wider spectrum of journals in citation analysis and keyword searching than PubMed and Web of Science [13]. It also offers an easy trajectory through the extrapolation of all the bibliometric indicators proposed in this study. The period 1994-2019 was chosen based on the fact that previous studies indicated that research on green pesticides has only become of increasing interest over the past two decades, due to increase in pesticides and agrochemicals residues which are causing significant contamination in the environment [14].

Due to the detrimental effects of synthetic pesticides on both the environment and human population, this study aims to carry out a descriptive bibliometric analysis on green pesticide research from 1994 to 2019, in order to present a general overview of global research trends towards finding an alternative for synthetic pesticides.

\section{Materials and Methods}

The published research outputs on botanical pesticides were retrieved from the Scopus database on 7 August 2020. The Scopus database provides access to 27 million abstracts with citations dating back to 1966 [15]. The key terms used to query Scopus database in this study were "plant pesticides", "plant biopesticides", "plant-derived pesticides", "green pesticides", "botanical pesticides" and "phyto-pesticides", using the Boolean operator "OR". These key terms were used to retrieve title-specific research from 1994 to 2019 which returned 586 documents. The documents were cleaned and downloaded in BibTex file format [16] and then analysed for a bibliometric statistics with $\mathrm{R}$-project version 4.0.2. The codes used to extract the bibliometric indices were in accordance with Aria and Cuccurullo [9] in Rstudio interface. The bibliometric indices, annual scientific production, article citation per year, bibliographic coupling, most productive authors, most productive countries, most relevant keywords, and most productive journals/source, were used in this study to evaluate the current and possible future trends of the research in plant biopesticides. In this study, the annual scientific indicator is tallied up by institute, organisation, author, and countries. The citation analysis measures the relative importance or impact of an author or publication has been cited by others. However, the citation counts were used to measure the impact per country on plant biopesticides. The publication-citation matrix was used to analyse most productive authors/countries, co-citation, and bibliographic coupling as described [9, 17]. The keywords extracted directly from the documents with the R-project interface are used to study the conceptual structure of the green pesticide research field.

\section{Results}

3.1. Green Pesticide Research Production. To determine the progression of research on green pesticides in this study, a wide spectrum of biopesticide keywords were used to query 
the database. A total of 540 published documents, from 332 sources, were recorded on green pesticides. These documents include articles, books, book chapters, conference papers, conference reviews, editorials, erratum, notes, reviews, and short surveys. An average citation of 12.63 per document makes them relevant in the scientific community (Table 1). The annual trend of scientific production from 1994 to 2008 showed a minimal increase, with the highest increases in 2000, 2004, and 2007 (Figure 1). Production increased significantly from 2009, with the most documents published in 2019 (74 documents). A decline in publications, however, occurred during 2015 and 2016, with 32 and 38 publications, respectively. The reason for such a decline is not known. The annual percentage growth rate from 1994 to 2019 was $13.68 \%$. It is also worth noting that although there is a steady increase in the annual scientific production, fluctuations do occur between some years. Possible explanations could include improved laboratories, the evolvement of new researchers, the development of new research methodology, and funding support [18].

3.2. Keywords on Green Pesticide Research. Most published documents contain a number of keywords to assist with online searches and identify certain editors to a document [18]. To study the research trends of green pesticides, both the singular and plural form of the author keywords were used. This aids in understanding the research evolution of the study field [19]. Both the author keywords and keyword plus were included in the study. The author keywords are a list of terms provided by the author/s that best represents the content of the document, while keyword-plus are terms or phrases that occur in the titles of a document's references but do not appear in the document's title itself [20]. Between 1994 and 2019, a total of 1732 author keywords and 4064 keyword-plus terms were retrieved from the documents on green pesticide research (Table 2). The most used author keyword was botanical pesticide/s occurring in 159 articles, followed by essential oil/s (41 articles) and pesticide/s (25 articles), second and third, respectively. Other author keywords occurring in the top 30 include green pesticides (22 articles), biopesticides (17 articles), pest management (14 articles), toxicity (12 articles), and plant extracts (13 articles) etc.; all these are relevant to pest control using plant biopesticides. The most used keyword-plus was animal/s, occurring in 220 articles, followed by pesticide/s (217 articles) and insecticide/s (175 articles), second and third, respectively, as shown in Table 2. It is not surprising to get a broad range of terms in keyword-plus because it is derived from the titles of documents cited by the author. Other keyword-plus terms in the top 30 are plant extract (102 articles), pest control (82 articles), essential oil (62 articles), and toxicity (38 articles). Although it is presumed that green pesticides are harmless to the environment, it is important to note that the keyword toxicity is listed in the top 30 of both the author keywords and keyword-plus terms, which could be referring to the potency of biopesticide plants. Most biopesticide plants are toxic but have a very short half-life [21]. This could have contributed to the general belief that plant biopesticides
TABLE 1: Summary of data retrieved from Scopus database.

\begin{tabular}{lc}
\hline Description & Count \\
\hline Documents & 540 \\
Source (journals, books, etc.) & 332 \\
Keywords plus (ID) & 4064 \\
Author's keywords (DE) & 1732 \\
Period & $1994-2019$ \\
Average citations per document & 12.63 \\
Authors & 1867 \\
Author appearances & 2408 \\
Authors of single-authored documents & 68 \\
Authors of multiauthored documents & 1799 \\
Single-authored documents & 79 \\
Documents per author & 0.311 \\
Authors per document & 3.22 \\
Co-authors per document & 4.15 \\
Collaboration index & 3.59 \\
\hline
\end{tabular}

are natural and therefore harmless, which is not always the case. In Figure 2, the co-occurrence network and interrelationship of the top 30 terms on green pesticide research are represented with a pictographic network. Each coloured circle represents a cluster of terms and the connecting lines represent the cooperation degree. Pesticide related terms are in blue clusters and the response related terms in red clusters (Figure 2).

\subsection{Productivity on Green Pesticide Research per Country.} India is ranked first in the most productive countries with a total of 98 publications, among which $4.08 \%$ are published out of collaboration. China and USA are ranked second and third with 68 and 32 publications, respectively. China has $2.94 \%$ and USA has $12.5 \%$ multiple country publications (MCP) which indicate the USA collaborates more while China relies more on local research. It is quite interesting to know that Italy and South Africa have fewer single country publications (SCP) compared to their MCP; hence they have a higher MCP: SCP ratio. The collaboration on publications of Italy, Netherlands, and South Africa is $60.86 \%, 75.0 \%$, and $80.0 \%$, respectively, making these the countries with the most collaboration network (Figure 3 ).

Table 3 shows that India is ranked first (1080 citations; h-index 18), followed by USA (979 citations; h-index 17) and Italy (868 citations; h-index 16), second and third, respectively. African countries in the top 30 list are Egypt in 8th (184 citations), South Africa 12th (92 citations), Zimbabwe 13th (90 citations), Nigeria 15th (69 citations), Kenya 20th (54 citations), and Tanzania 22nd (52 citations). It is debated that citations reflect the scientific impact and relevance of an article, but with limitation to the measures of the research quality $[22,23]$. Hence, the citation ranking the USA first and other countries following could be the measure of their study relevancy. It is important to note that Europe is the largest consumer of pesticides with Asia the second largest and the leading countries in pesticide production are China, USA, France, Brazil, and Japan [24]. In Figure 3 and Table 3, the above-mentioned countries are ranked in the top 30 of the categories of the most productive and most cited country 


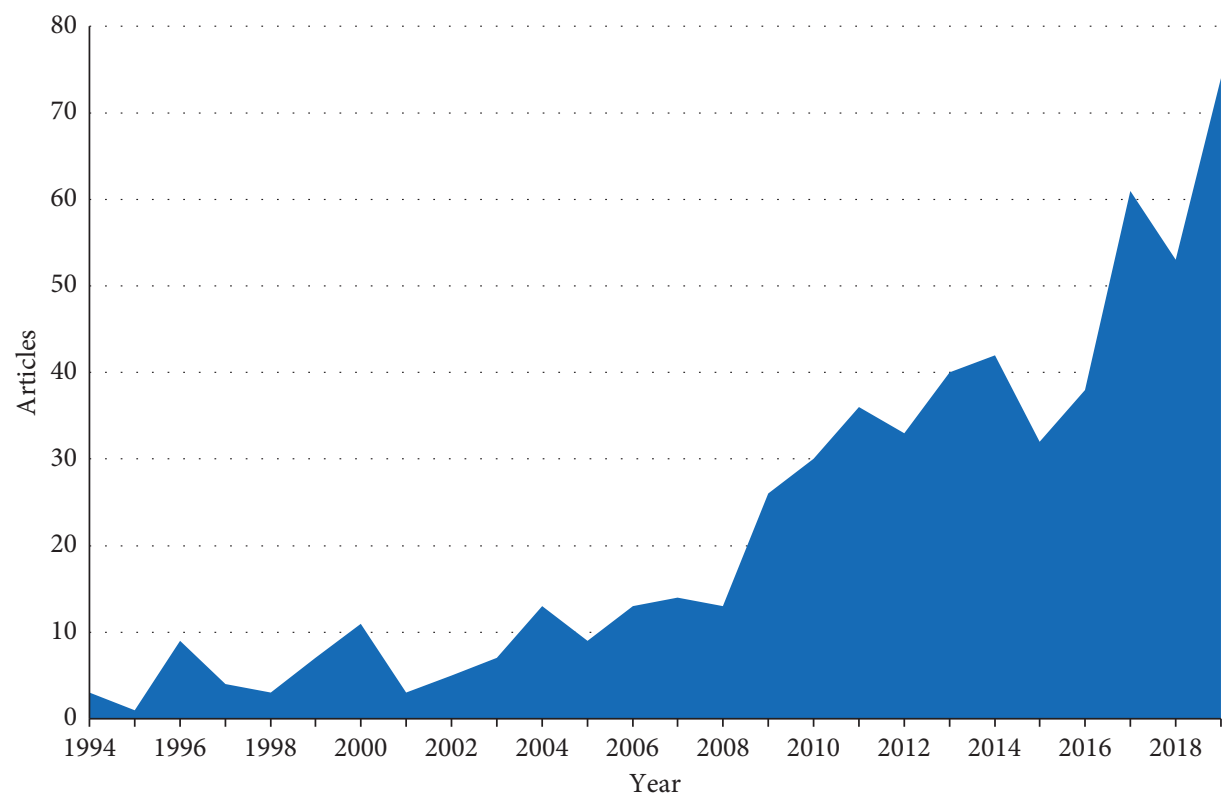

Figure 1: Annual scientific publications of documents on plant biopesticides from 1994 to 2019 in the Scopus database.

TABLE 2: Top 30 most relevant keywords on green pesticide research from 1994 to 2019.

\begin{tabular}{|c|c|c|c|c|}
\hline Rank & Author keywords (DE) & Articles & Keyword plus (ID) & Articles \\
\hline 1 & Botanical pesticide/s & 159 & Animal/s & 220 \\
\hline 2 & Essential oil/s & 41 & Pesticide/s & 217 \\
\hline 3 & Pesticide/s & 25 & Insecticide/s & 175 \\
\hline 4 & Azadirachtin & 24 & Plant extract/s & 151 \\
\hline 5 & Green pesticides & 22 & Article & 117 \\
\hline 6 & Biopesticides & 17 & Chemistry & 90 \\
\hline 7 & Neem & 15 & Pest control & 82 \\
\hline 8 & Pest management & 14 & Hexapoda & 79 \\
\hline 9 & Botanical insecticide/s & 14 & Nonhuman & 78 \\
\hline 10 & Azadirachta indica & 13 & Drug effect & 69 \\
\hline 11 & Botanicals & 13 & Azadirachta indica & 65 \\
\hline 12 & Plant extracts & 13 & Essential oil & 62 \\
\hline 13 & Spodoptera litura & 12 & Botanical pesticides & 60 \\
\hline 14 & Toxicity & 12 & Controlled study & 57 \\
\hline 15 & Mortality & 11 & Larva & 50 \\
\hline 16 & Integrated pest management & 10 & Biopesticide & 49 \\
\hline 17 & Antifeedant & 9 & Unclassified drug & 43 \\
\hline 18 & Biological control & 9 & Female & 42 \\
\hline 19 & Insecticidal activity & 9 & Lepidoptera & 39 \\
\hline 20 & Repellency & 9 & Metabolism & 38 \\
\hline 21 & Bioassay & 8 & Toxicity & 38 \\
\hline 22 & Contact toxicity & 8 & Human & 37 \\
\hline 23 & Insecticide & 8 & Bioassay & 35 \\
\hline 24 & Pest control & 8 & Agriculture & 33 \\
\hline 25 & Aphids & 6 & Biological control & 33 \\
\hline 26 & Heteropneustes fossilis & 6 & Insect & 32 \\
\hline 27 & Phytochemicals & 6 & Mortality & 32 \\
\hline 28 & Plutella xylostella & 6 & Fungi & 31 \\
\hline 29 & Tetranychus urticae & 6 & Moth & 31 \\
\hline 30 & Acute toxicity & 5 & Physiology & 27 \\
\hline
\end{tabular}




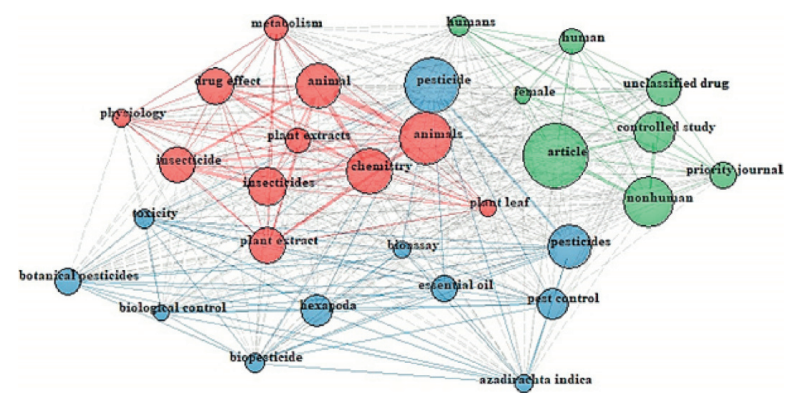

FIGURE 2: Keyword co-occurrences network of the top 30 keywords on green pesticide research. The circle size of the keywords represents the frequency of occurrence in articles. The thickness of the line between any two keywords displays the degree of cooperation.

in plant biopesticide study, but with the exception of Japan, indicating the countries are focusing on plant biopesticides as an alternative to synthetic pesticides, and these studies are relevant in the scientific community [25].

According to Lee and Bozeman [26], scientific collaboration in research has become the standard. Modern science is becoming ever more interdisciplinary and complex, which encourages research collaboration. Many funding agencies encourage collaborative research by incorporating this as one of their funding conditions [26]. The top 30 country collaboration network on green pesticides is shown in Figure 4. The coloured circles represent the countries and the circle size represents the number of collaborations with other countries. Thicker lines between countries illustrate collaborative strength between countries. As revealed by the bibliometric analysis, Italy, United Kingdom, USA, Canada, South Africa, India, and Netherlands have the most collaborations with other countries. Figure 4 shows the frequency and network of collaboration between the countries. India, United Kingdom, Netherlands, Brazil, Canada, and the USA collaborate often. Italy, Czech Republic, Saudi Arabia, and India are regular collaborators. And Netherlands, South Africa, and the USA also frequently collaborate, all these forming a network. The collaborative strength of some of these countries could be ascribed to the respective countries history of pesticide use and government funding encouraging collaboration [18].

\subsection{Most Cited Documents on Green Pesticides and Source} Impact. Table 4 presents the most cited papers on plant biopesticides. The top-ranked article published by Pavela and Benelli [27] had a total of 288 citations at an average of 57.6 citations per year. In the article, the strengths, challenges, and constraints of essential oil-based biopesticides were analysed [27], considering the effectiveness, toxicity, and the mechanisms of action. The high citation accredited by the article may be due to the wide spectrum of the biological activity such as nematicidal, ovicidal, fungicidal, insecticidal, and bactericidal effect of essential oil-based biopesticides making the article relevant in a wide field of research. Surprisingly, only 3 articles from the 1990s are listed in the top 30 most cited documents. This may indicate that more recent researchers are becoming more interested in plant biopesticides, as search for alternative synthetic pesticides grows.

In Table 5, the top 30 productive journals in terms of the number of publications, total citations, and h-index are reported. The top 30 journals have published 219 articles which represent $37.76 \%$ of the documents in this study. The Pestology journal is ranked first (NP: 24; h-index; 4), Industrial Crops and Products second (NP: 21; h-index: 12), and Pest Management Science third (NP: 14; h-index: 10). The source growth of the top 10 productive journals is shown in Figure 5. The journals "Environmental Science and Pollution Research," "Industrial Crops and Products," and 'Scientific Reports" have grown exponentially over the last few years. On the contrary, the impact of the journals "Pestology," "Acta Horticulture," and "Advances in Plant Biopesticides" has drastically reduced in the field of plant biopesticides over time. It is also noteworthy that 25 years ago very few journals published articles on green pesticides. Recently, there are more publications on green pesticides indicating that the research area is growing.

\section{Discussion}

The increase in publications from 2009 could be due to the increasing realization of the detrimental effects of synthetic pesticides on the environment [1], the growing need for a sustainable alternative, government policies on environmental protection, and pressure groups [56].

To determine the productivity of a research field based on a bibliometric study, the number of scientific publications is investigated [57]. Globally, demand for biopesticides has increased due to rising interest in organic products as a potential alternative to synthetic insecticides [58]. The demand could have driven the raising research and publication in the field of plant biopesticides as shown in Figure 1. Andreo-Martínez et al. [59] in their study reported an increase of publication related to pesticides bioavailability in food, vegetables, and wine from 1 in 1976 to 154 in 2018 [59]. This is in accordance with our study as there is a steady and sharp increase in the publication of biopesticides related work from 2009. A change in the number of publications in a research field could indicate a possible change in demand and technology. In Table 2, the keyword-plus "animal/s" is ranked first. This could be due to the increasing demand and use of plant phytochemicals for ectoparasites on livestock [60]. The use of plant biopesticides is common especially among rural areas communities that are dependent on livestock for survival. Aside from the cultural practices, these communities often do not have the financial capability to buy pesticides and instead make use of biopesticides for pest management [60].

Considering the data collected in this study as shown in Table 1, a total of 580 documents from 332 sources were retrieved from the Scopus database. These documents were authored by 1867 researchers, on green pesticides from 1994 to 2019 with an estimate of 0.311 documents per author and 3.22 authors per document. Out of the 1867 authors, 1799 were authors of multi-authored documents with the remaining 68 being authors of single-authored documents. 


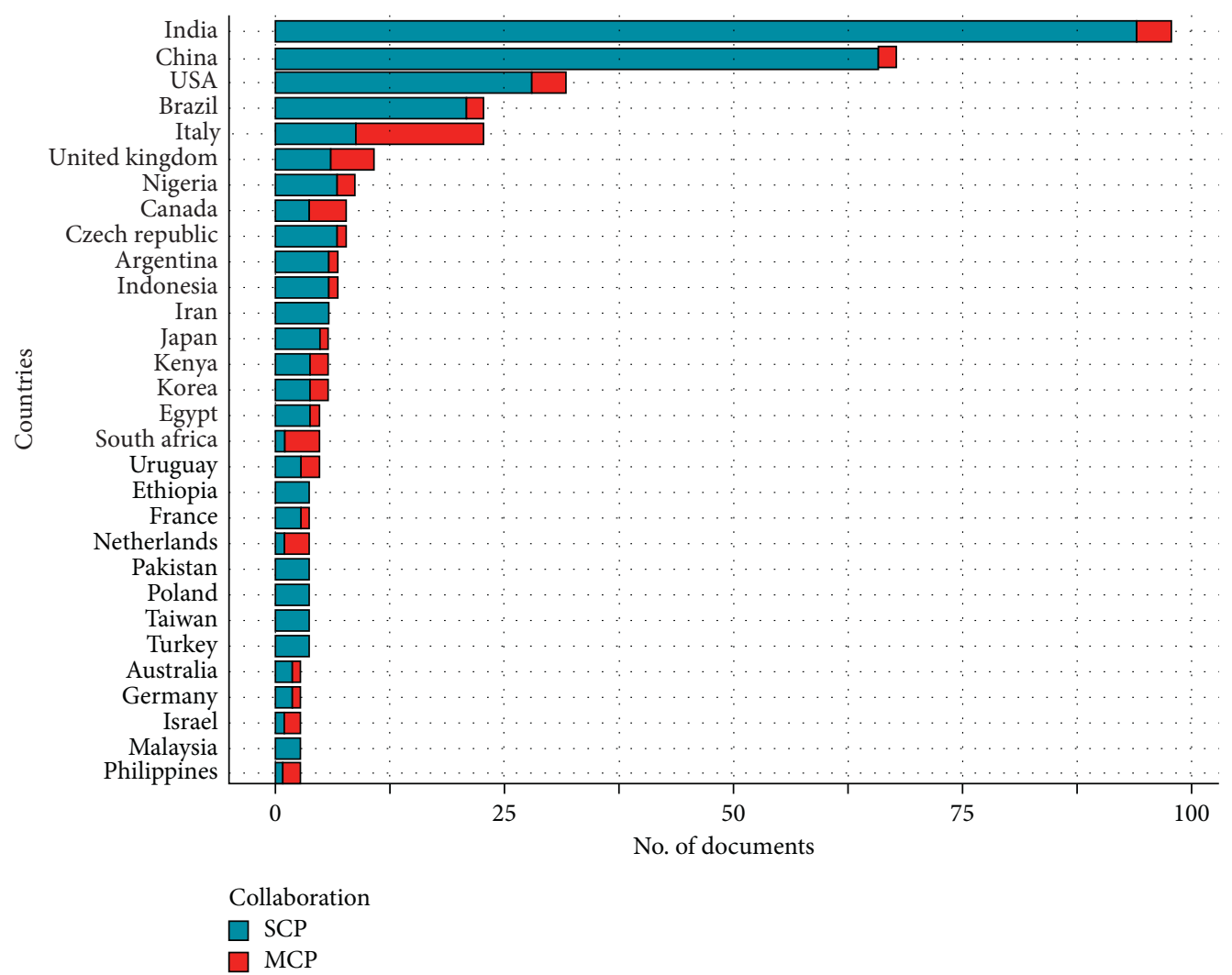

Figure 3: Most productive countries and collaboration in the research of green pesticides from 1994 to 2019. SCP: Single Country Publications, MCP: Multiple Country Publications.

TABLE 3: Citations per country in terms of green pesticide research from 1994 to 2019.

\begin{tabular}{|c|c|c|c|c|c|}
\hline Rank & Country/region & Total citations & Average article citations (\%) & MCP ratio & h-index \\
\hline 1 & India & 1080 & 11.020 & 0.041 & 18 \\
\hline 2 & USA & 979 & 30.594 & 0.125 & 17 \\
\hline 3 & Italy & 868 & 37.739 & 0.609 & 16 \\
\hline 4 & China & 682 & 10.029 & 0.029 & 14 \\
\hline 5 & United Kingdom & 441 & 40.091 & 0.455 & 11 \\
\hline 6 & Brazil & 389 & 16.913 & 0.087 & 10 \\
\hline 7 & Canada & 251 & 31.375 & 0.500 & 9 \\
\hline 8 & Egypt & 184 & 36.800 & 0.200 & 7 \\
\hline 9 & Argentina & 162 & 23.143 & 0.143 & 7 \\
\hline 10 & Belgium & 105 & 52.500 & 1.000 & 6 \\
\hline 11 & Czech Republic & 94 & 11.750 & 0.125 & 5 \\
\hline 12 & South Africa & 92 & 18.400 & 0.800 & 5 \\
\hline 13 & Zimbabwe & 90 & 45.000 & 1.000 & 5 \\
\hline 14 & Iran & 86 & 14.333 & 0 & 5 \\
\hline 15 & Nigeria & 69 & 7.667 & 0.222 & 4 \\
\hline 16 & Korea & 68 & 11.333 & 0.333 & 4 \\
\hline 17 & Uruguay & 64 & 12.800 & 0.400 & 4 \\
\hline 18 & Turkey & 59 & 14.750 & 0 & 4 \\
\hline 19 & Israel & 55 & 18.333 & 0.667 & 4 \\
\hline 20 & Kenya & 54 & 9.000 & 0.333 & 4 \\
\hline 21 & Netherlands & 52 & 13.000 & 0.750 & 4 \\
\hline 22 & Tanzania & 52 & 17.333 & 0.667 & 4 \\
\hline 23 & Poland & 44 & 11.000 & 0 & 3 \\
\hline 24 & Romania & 44 & 44.000 & 0 & 3 \\
\hline 25 & Australia & 42 & 14.000 & 0.333 & 3 \\
\hline 26 & Taiwan & 39 & 9.750 & 0 & 3 \\
\hline 27 & France & 38 & 9.500 & 0.250 & 3 \\
\hline 28 & Greece & 38 & 38.000 & 0 & 3 \\
\hline 29 & Germany & 27 & 9.000 & 0.333 & 2 \\
\hline 30 & Lebanon & 27 & 27.000 & 0 & 2 \\
\hline
\end{tabular}

MCPs: multiple country publications. 


\section{Country Collaboration}

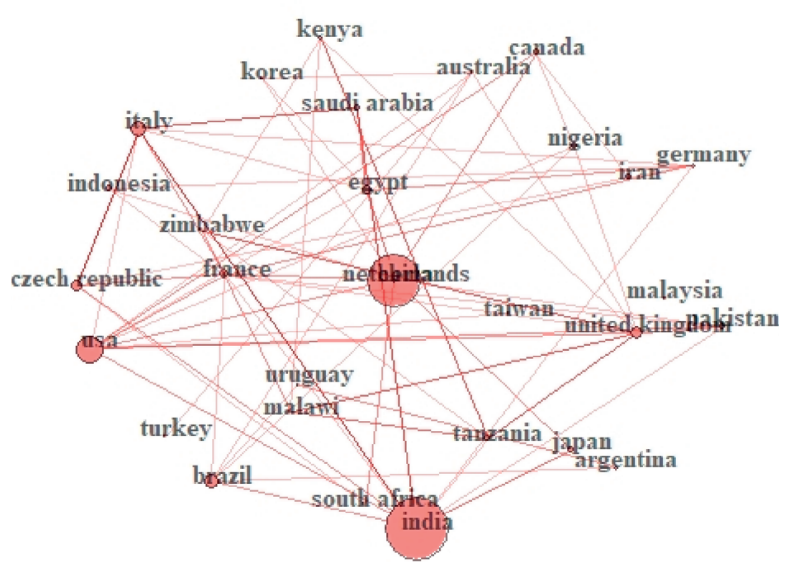

Figure 4: Country collaboration network of the top 30 most productive countries on green pesticide research. Line thickness represents the collaboration strength between countries.

TABle 4: The top 30 most cited documents on green pesticide research from 1994 to 2019 from Scopus.

\begin{tabular}{|c|c|c|c|c|}
\hline Rank & First authors & Journal & TC & TC/year \\
\hline 1 & Pavela Roman, 2016 & Trends Plant Sci & 288 & 57.6 \\
\hline 2 & Mulla S. Mir, 1999 & J Am Mosq Control Assoc & 242 & 11.0 \\
\hline 3 & Morgan E. David, 2009 & Bioorg Med Chem & 161 & 13.42 \\
\hline 4 & Son T. Gen, 2010 & J Neurochem & 135 & 12.27 \\
\hline 5 & Miresmailli Saber, 2014 & Trends Plant Sci & 134 & 19.14 \\
\hline 6 & Dodge Jeffrey A, 1996 & J Steroid Biochem Mol Biol & 130 & 5.2 \\
\hline 7 & Benelli Giovanni, 2017 & J Cluster Sci & 101 & 25.25 \\
\hline 8 & Attia Sabrine, 2013 & J Pest Sci & 99 & 12.37 \\
\hline 9 & El-Wakeil Nabil E, 2013 & Gesunde Pflanz & 95 & 11.87 \\
\hline 10 & Qian Xuhong, 2010 & J Agric Food Chem & 89 & 8.09 \\
\hline 11 & Cresswell James E, 2012 & Pest Manage Sci & 71 & 7.89 \\
\hline 12 & Sibanda T, 2000 & Crop Prot & 71 & 3.38 \\
\hline 13 & Mossa Abdel Tawab H, 2016 & J Environ Sci Technol & 68 & 13.6 \\
\hline 14 & Koul Opender, 2009 & Cab Rev Perspect Agric Vet Sci Nutr Nat Resour & 68 & 5.67 \\
\hline 15 & Kotkar Hemlata M, 2002 & Pest Manage Sci & 68 & 3.58 \\
\hline 16 & Charleston Deidre S, 2005 & Biol Control & 64 & 4.0 \\
\hline 17 & Martin Krista M, 2000 & J Am Vet Med Assoc & 64 & 3.05 \\
\hline 18 & Benelli Giovanni, 2017 & Parasitol Int & 62 & 15.5 \\
\hline 19 & Hunt Piper R, 2011 & Plos One & 62 & 6.2 \\
\hline 20 & Dubey NK, 2010 & Curr Sci & 61 & 5.55 \\
\hline 21 & Zheng Ke, 2012 & Acta Chim Sin & 60 & 6.67 \\
\hline 22 & Mann Rs, 2012 & Mini-Rev Org Chem & 59 & 6.56 \\
\hline 23 & Rao K Jagajjanani, 2013 & Rsc Adv & 56 & 7.0 \\
\hline 24 & Vidal Estrela Joelma Lima, 2006 & Pesqui Agropecu Bras & 54 & 3.6 \\
\hline 25 & Benelli Giovanni, 2018 & Ind Crops Prod-A & 53 & 17.67 \\
\hline 26 & Caboni Pierluigi, 2012 & J Agric Food Chem & 51 & 5.67 \\
\hline 27 & Zibaee A, 2010 & Bull Entomol Res & 51 & 4.64 \\
\hline 28 & Moreira Márcio D, 2007 & Pest Manage Sci & 51 & 3.64 \\
\hline 29 & Mansour F, 2004 & Phytoparasitica & 50 & 2.94 \\
\hline 30 & Valladares G, 1997 & J Econ Entomol & 49 & 2.04 \\
\hline
\end{tabular}

$\mathrm{TC}=$ total citations.

The average number of authors per document is referred to as collaboration index [61]. Research collaboration and country collaboration network as shown in Figures 3 and 4 of this study are the bibliometric indicators that reflect the social structure among countries, institutions, and researchers. Many previous bibliometric studies in different fields ranked the United States as being dominant in international collaboration $[62,63]$; on the contrary, our analysis reveals Italy dominates international collaboration on green biopesticide followed by the United Kingdom. International research collaboration allows a synergy of knowledge, idea, and research fund that enhances the quality 
TABLE 5: Top 30 productive journals, the total number of publications, total citations, h-index, and publication start year, from 1994 to 2019.

\begin{tabular}{|c|c|c|c|c|}
\hline Source & NP & TC & h-index & PY-Start \\
\hline Pestology & 24 & 48 & 4 & 1996 \\
\hline Industrial Crops and Products & 21 & 334 & 12 & 2010 \\
\hline Pest Management Science & 14 & 378 & 10 & 2000 \\
\hline Environmental Science and Pollution Research & 13 & 155 & 6 & 2010 \\
\hline Advances in Plant Biopesticides & 13 & 91 & 7 & 2014 \\
\hline Journal of Agricultural and Food Chemistry & 12 & 342 & 8 & 2003 \\
\hline Crop Protection & 10 & 258 & 9 & 1997 \\
\hline Acta Horticulturae & 10 & 20 & 2 & 1997 \\
\hline Scientific Reports & 9 & 75 & 5 & 2016 \\
\hline Journal of Biopesticides & 8 & 28 & 4 & 2010 \\
\hline Plos One & 7 & 150 & 5 & 2006 \\
\hline Journal of Pest Science & 6 & 172 & 6 & 2009 \\
\hline Molecules & 6 & 39 & 4 & 2010 \\
\hline Green Pesticides Handbook: Essential Oils for Pest Control & 6 & 5 & 2 & 2017 \\
\hline ACS Symposium Series & 5 & 50 & 2 & 1996 \\
\hline Journal of Pesticide Science & 5 & 23 & 3 & 2009 \\
\hline Biopesticides International & 5 & 5 & 2 & 2011 \\
\hline Phytoparasitica & 4 & 85 & 3 & 2004 \\
\hline Pesticide Biochemistry and Physiology & 4 & 54 & 3 & 2011 \\
\hline Journal of Insect Science & 4 & 28 & 2 & 2014 \\
\hline Archives of Phytopathology and Plant Protection & 4 & 16 & 2 & 2011 \\
\hline Zhongguo Zhongyao Zazhi & 4 & 7 & 2 & 2004 \\
\hline IOP Conference Series: Earth and Environmental Science & 4 & 2 & 1 & 2018 \\
\hline Trends in Plant Science & 3 & 426 & 3 & 2014 \\
\hline Journal of Economic Entomology & 3 & 92 & 3 & 1997 \\
\hline Medical and Veterinary Entomology & 3 & 76 & 3 & 2008 \\
\hline Phytochemistry Reviews & 3 & 61 & 3 & 2011 \\
\hline International Journal of Tropical Insect Science & 3 & 49 & 2 & 2006 \\
\hline Ecotoxicology and Environmental Safety & 3 & 31 & 2 & 2010 \\
\hline ACS Sustainable Chemistry and Engineering & 3 & 26 & 2 & 2016 \\
\hline
\end{tabular}

NP: number of publications; TC: total citations; PY-Start: publication year start.

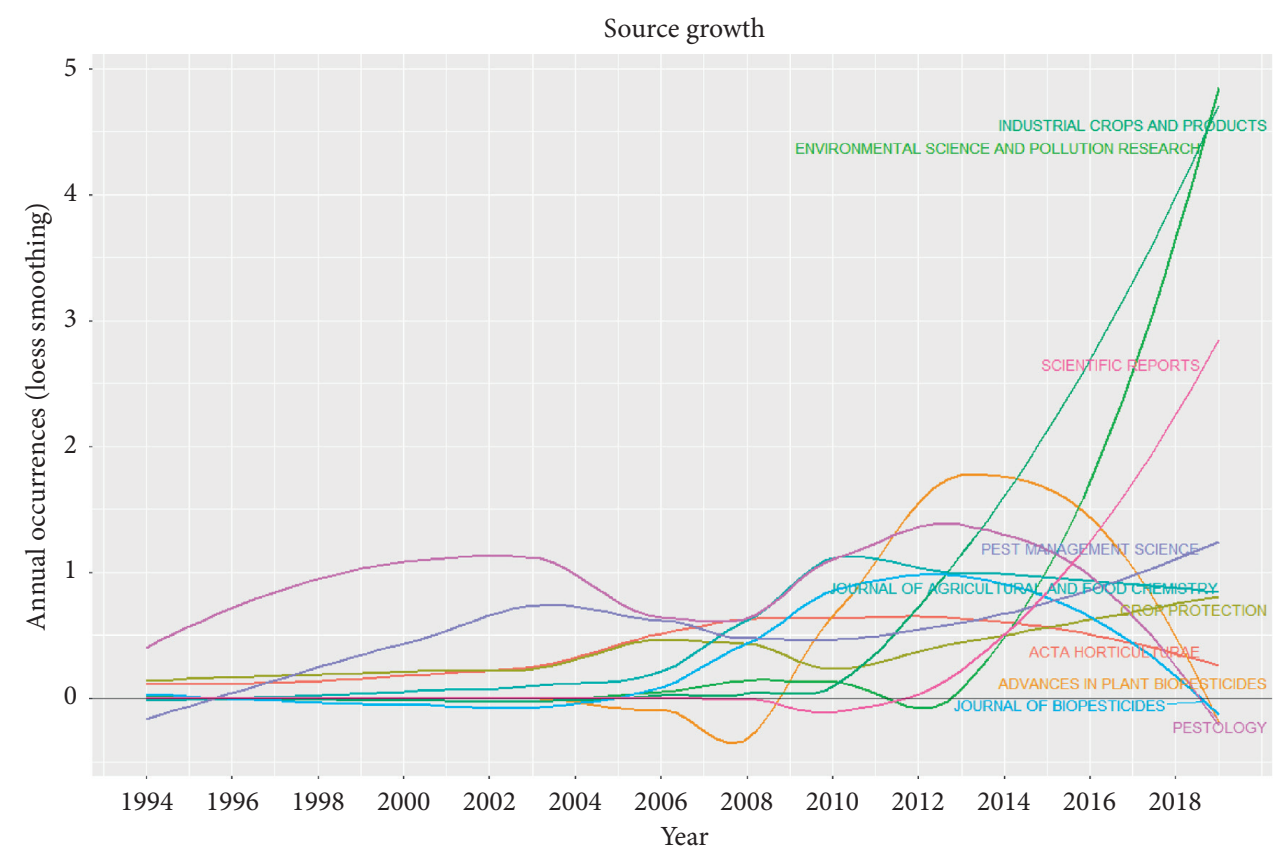

FIGURE 5: Source growth of the top 10 most productive journals from 1994 to 2019. 
of research. Collaboration has a great impact on the citation of a document; particularly internationally co-authored papers were reported to receive twice the average citation as local co-authored papers [64]. India, however, tops the most cited countries on green biopesticide papers and most of these countries in Table 3 are also reported in the previous bibliometric study of pesticides [59]. The collaboration index (CI) for green biopesticide as established in this study is 3.59, which is considered as high participation of co-authorship [61]. A study by Liu et al. [24] on global biodiversity research reported the worldwide research collaboration index to be 4.45 [24], which is higher than the CI reported in this study. The CI of global biodiversity research as reported could be the ripple effect of climate change which is a major driver of biodiversity [65].

In Figure 3, India and China are ranked first and second, respectively, in green pesticide research; this may be attributed to their long history of the use of botanical insecticides [3]. The African continent has 5 countries in the top 30 most productive countries: Nigeria (7th), Kenya (14th), Egypt (16th), South Africa (17th), and Ethiopia (19th) with $9,6,5,5$, and 4 publications, respectively. Although Africa consumes less than $5 \%$ of global pesticides, most countries in Africa still use the most toxic pesticides in food production [66]. According to Dinham [67], small-scale farmers apply these toxic pesticides weekly, sometimes more often, during the growing season [67]. This raises a number of concerns to both environmental and human health experts in Africa. Finally, the above-mentioned factors indicate that African countries are not doing enough in pesticide regulations and the research towards an alternative which means the continent still needs to do more in pest management while jacking up crop production.

The limitations that arose during this study were language, the fact that the quality of published documents could not be ascertained, and the research not available on Scopus being missed out. The documents retrieved from the Scopus database were limited to "English written documents." Documents published in other languages also contribute to research productivity but were unfortunately eliminated in this study. The quality of published documents cannot be measured by total citations alone while the annual scientific production of an author or a country is also not a measure of research quality [18]. It is worth noting that bibliometric analysis does not criticize any part of a research document; hence quality control could be problematic. Regardless of the limitations associated with this study, it provided a global overview of green pesticide research productivity from 1994 to 2019 .

\section{Conclusion}

This bibliometric study discussed the global trend of green pesticide research from 1994 to 2019 based on documents retrieved from Scopus. Despite the increasing research on green pesticides, commercial applications remain limited. Trends in the annual scientific production suggest that research on green pesticides will continue to increase. The detrimental effects of synthetic pesticides on the environment and human health could be the possible drivers for research productivity in the alternative field of plant biopesticides. This study also found that India, China, and USA are the leading countries in the production of green biopesticide research documents articles and amass the highest total citations per country. Countries in Europe and Africa, although high consumers of pesticides, have significantly less published research documents compared to the earlier mentioned countries. Europe and Africa countries need to intensify their research on alternative pesticides through either government or privately funded programs to promote environmentally friendly pesticides, especially in Africa where pesticides with high toxicity are still being used.

\section{Data Availability}

Data are available on request to the corresponding author.

\section{Conflicts of Interest}

The authors declare that they have no conflicts of interest.

\section{References}

[1] I. Mahmood, S. R. Imadi, K. Shazadi, A. Gul, and K. R. Hakeem, "Effects of pesticides on environment," in Plant, Soil and Microbes: Volume 1: Implications in Crop Science, pp. 253-269, Springer, Berlin, Germany, 2016.

[2] S. Lima, S. Saha, V. Tripathi, and K. K. Sharma, "Phytochemical biopesticides: some recent developments," Phytochemistry Reviews, vol. 16, 2017.

[3] M. B. Isman, "Botanical insecticides, deterrents, and repellents IN modern agriculture and an increasingly regulated world," Annual Review of Entomology, vol. 51, no. 1, pp. 45-66, 2006.

[4] M. B. Isman and M. L. Grieneisen, "Botanical insecticide research: many publications, limited useful data," Trends in plant science, vol. 19, 2014.

[5] O. Koul, S. Walia, and G. S. Dhaliwal, "Essential oils as green pesticides: potential and constraints," Biopesticides International, vol. 4, pp. 63-84, 2008.

[6] E. V. R. Campos, P. L. F. Proença, J. L. Oliveira, M. Bakshi, P. C. Abhilash, and L. F. Fraceto, "Use of botanical insecticides for sustainable agriculture: future perspectives," Ecological Indicators, vol. 105, pp. 483-495, 2019.

[7] A. M. Grumezescu, New Pesticides and Soil Sensors, Academic Press, Cambridge, MA, USA, 2017.

[8] M. B. Isman, "Commercial development of plant essential oils and their constituents as active ingredients in bioinsecticides," Phytochemistry Reviews, vol. 19, no. 2, pp. 235-241, 2020.

[9] M. Aria and C. Cuccurullo, "Bibliometrix: an R-tool for comprehensive science mapping analysis," Journal of Informetrics, vol. 11, no. 4, pp. 959-975, 2017.

[10] G. Bao, L. Pan, H. Fang et al., "Academic review and perspectives on robotic exoskeletons," IEEE Transactions on Neural Systems and Rehabilitation Engineering, vol. 27, no. 11, pp. 2294-2304, 2019.

[11] L. He, H. Fang, C. Chen et al., "Metastatic castration-resistant prostate cancer: academic insights and perspectives through bibliometric analysis," Medicine (Baltimore), vol. 99, 2020.

[12] P. K. Muhuri, A. K. Shukla, and A. Abraham, "Industry 4.0: a bibliometric analysis and detailed overview," Engineering 
Applications of Artificial Intelligence, vol. 78, pp. 218-235, 2019.

[13] M. E. Falagas, E. I. Pitsouni, G. A. Malietzis, and G. Pappas, "Comparison of PubMed, Scopus, Web of science, and google scholar: strengths and weaknesses," The FASEB Journal, vol. 22, no. 2, pp. 338-342, 2008.

[14] F. P. Carvalho, "Pesticides, environment, and food safety," Food and Energy Security, vol. 6, no. 2, pp. 48-60, 2017.

[15] J. F. Burnham, "Scopus database: a review," Biomedical Digital Libraries, vol. 3, 2006.

[16] R. Larayetan, C. Olisah, and O. A. Idris, "Research progression on studies related to green synthesis nanoparticles: a bibliometric review," in Green Synthesis of Nanoparticles: Applications and Prospects, pp. 1-22, Springer, Berlin, Germany, 2020.

[17] A. Perianes-Rodriguez, L. Waltman, and N. J. van Eck, "Constructing bibliometric networks: a comparison between full and fractional counting," Journal of Informetrics, vol. 10, no. 4, pp. 1178-1195, 2016.

[18] C. Olisah, O. O. Okoh, and A. I. Okoh, "Global evolution of organochlorine pesticides research in biological and environmental matrices from 1992 to 2018: a bibliometric approach," Emerging Contaminants, vol. 5, 2019.

[19] I. Cañas-Guerrero, F. R. Mazarrón, A. Pou-Merina, C. CallejaPerucho, and G. Díaz-Rubio, "Bibliometric analysis of research activity in the "Agronomy" category from the Web of Science, 1997-2011," European Journal of Agronomy, vol. 50, pp. 19-28, 2013.

[20] J. Zhang, Q. Yu, F. Zheng, C. Long, Z. Lu, and Z. Duan, "Comparing keywords plus of WOS and author keywords: a case study of patient adherence research," Journal of the Association for Information Science and Technology, vol. 67, no. 4, pp. 967-972, 2016.

[21] H. Y. Kang, Z. S. Othman, and S. I. Zubairi, "Accumulation of biopesticide-based rotenone from an optimized [BMIM] [OTf] green binary solvent mixture in different parts of terong plant (solanum melongena)," in Procedia Engineering, pp. 702-709, Elsevier, Amsterdam, Netherlands, 2016.

[22] D. W. Aksnes, L. Langfeldt, and P. Wouters, "Citations, citation indicators, and research quality: an overview of basic concepts and theories," SAGE Open, vol. 9, no. 1, 2019.

[23] P. Nieminen, J. Carpenter, G. Rucker, and M. Schumacher, "The relationship between quality of research and citation frequency," BMC Medical Research Methodology, vol. 6, 2006.

[24] X. Liu, L. Zhang, and S. Hong, "Global biodiversity research during 1900-2009: a bibliometric analysis," Biodiversity and Conservation, vol. 20, no. 4, pp. 807-826, 2011.

[25] T. Riss, A. Niles, R. Moravec, N. Karassina, and J. Vidugiriene, "Cytotoxicity assays: in vitro methods to measure dead cells," in Assay Guidance Manual, 2019.

[26] S. Lee and B. Bozeman, "The impact of research collaboration on scientific productivity," Social Studies of Science, vol. 35, no. 5, pp. 673-702, 2005.

[27] R. Pavela and G. Benelli, "Essential oils as ecofriendly biopesticides? Challenges and constraints," Trends in Plant Science, vol. 12, 2016.

[28] M. S. Mulla and T. Su, "Activity and biological effects of neem products against arthropods of medical and veterinary importance," Journal of the American Mosquito Control Association, vol. 15, no. 2, pp. 133-152, 1999.

[29] E. D. Morgan, "Azadirachtin, a scientific gold mine," Bioorganic \& Medicinal Chemistry, vol. 17, no. 12, pp. 4096-4105, 2009.
[30] T. G. Son, S. Camandola, T. V. Arumugam et al., "Plumbagin, a novel Nrf2/ARE activator, protects against cerebral ischemia," Journal of Neurochemistry, vol. 112, no. 5, pp. 1316-1326, 2010.

[31] S. Miresmailli and M. B. Isman, "Botanical insecticides inspired by plant-herbivore chemical interactions," Trends in Plant Science, vol. 19, no. 1, pp. 29-35, 2014.

[32] J. A. Dodge, A. L. Glasebrook, D. E. Magee et al., "Environmental estrogens: effects on cholesterol lowering and bone in the ovariectomized rat," The Journal of Steroid Biochemistry and Molecular Biology, vol. 59, no. 2, pp. 155-161, 1996.

[33] G. Benelli, R. Pavela, F. Maggi, R. Petrelli, and M. Nicoletti, "Commentary: making green pesticides greener? The potential of plant products for nanosynthesis and pest control," Journal of Cluster Science, vol. 28, no. 1, pp. 3-10, 2017.

[34] S. Attia, K. L. Grissa, G. Lognay, E. Bitume, T. Hance, and A. C. Mailleux, "A review of the major biological approaches to control the worldwide pest Tetranychus urticae (Acari: tetranychidae) with special reference to natural pesticides," Journal of Pest Science, vol. 86, no. 3, pp. 361-386, 2013.

[35] N. E. El-Wakeil, "Retracted article: botanical pesticides and their mode of action," Gesunde Pflanzen, vol. 65, no. 4, pp. 125-149, 2013.

[36] X. Qian, P. W. Lee, and S. Cao, "China: forward to the green pesticides via a basic research program $\dagger$," Journal of Agricultural and Food Chemistry, vol. 58, no. 5, pp. 2613-2623, 2010.

[37] J. E. Cresswell, N. Desneux, and D. vanEngelsdorp, "Dietary traces of neonicotinoid pesticides as a cause of population declines in honey bees: an evaluation by Hill's epidemiological criteria," Pest Management Science, vol. 68, no. 6, pp. 819-827, 2012.

[38] T. Sibanda, H. M. Dobson, J. F. Cooper, W. Manyangarirwa, and W. Chiimba, "Pest management challenges for smallholder vegetable farmers in Zimbabwe," Crop Protection, vol. 19, no. 8-10, pp. 807-815, 2000.

[39] A.-T. H. Mossa, "Green Pesticides: essential oils as biopesticides in insect-pest management," Journal of Environmental Science and Technology, vol. 9, no. 5, pp. 354-378, 2016.

[40] O. Koul and S. Walia, "Comparing impacts of plant extracts and pure allelochemicals and implications for pest control," CAB Reviews: Perspectives in Agriculture, Veterinary Science, Nutrition and Natural Resources, vol. 4, pp. 1-30, 2009.

[41] H. M. Kotkar, P. S. Mendki, S. V. G. S. Sadan, S. R. Jha, S. M. Upasani, and V. L. Maheshwari, "Antimicrobial and pesticidal activity of partially purified flavonoids ofAnnona squamosa," Pest Management Science, vol. 58, no. 1, pp. 33-37, 2002.

[42] D. S. Charleston, R. Kfir, M. Dicke, and L. E. M. Vet, "Impact of botanical pesticides derived from Melia azedarach and Azadirachta indica on the biology of two parasitoid species of the diamondback moth," Biological Control, vol. 33, no. 2, pp. 131-142, 2005.

[43] K. M. Martin, M. A. Rossing, L. M. Ryland, R. F. DiGiacomo, and W. A. Freitag, "Evaluation of dietary and environmental risk factors for hyperthyroidism in cats," Journal of the American Veterinary Medical Association, vol. 217, no. 6, pp. 853-856, 2000.

[44] P. R. Hunt, T. G. Son, M. A. Wilson et al., "Extension of lifespan in C. elegans by naphthoquinones that act through stress hormesis mechanisms," PLoS One, vol. 6, Article ID e21922, 2011. 
[45] N. K. Dubey, R. Shukla, A. Kumar, P. Singh, and B. Prakash, "Prospects of botanical pesticides in sustainable agriculture," Current Science, vol. 98, pp. 479-480, 2010.

[46] K. Zheng, L. Lin, and X. Feng, "ChiralN,N'-Dioxide-Ni(II) complex catalyzed asymmetric carbonyl-ene reaction of ethyl trifluoropyruvate," Acta Chimica Sinica, vol. 70, no. 17, pp. 1785-1790, 2012.

[47] R. S. Mann and P. E. Kaufman, "Natural product pesticides: their development, delivery and use against insect vectors," Mini-Reviews in Organic Chemistry, vol. 9, pp. 185-202, 2012.

[48] K. J. Rao and S. Paria, "Use of sulfur nanoparticles as a green pesticide on Fusarium solani and Venturia inaequalis phytopathogens," RSC Advances, vol. 3, no. 26, pp. 10471-10478, 2013.

[49] J. L. V. Estrela, M. Fazolin, V. Catani, and M. R. Alécio, "Toxicidade de óleos essenciais de Piper aduncum e Piper hispidinervum em Sitophilus zeamais," Pesquisa Agropecuária Brasileira, vol. 41, no. 2, pp. 217-222, 2006.

[50] G. Benelli, R. Pavela, R. Petrelli et al., "The essential oil from industrial hemp (Cannabis sativa L.) by-products as an effective tool for insect pest management in organic crops," Industrial Crops and Products, vol. 122, pp. 308-315, 2018.

[51] P. Caboni, N. G. Ntalli, N. Aissani, I. Cavoski, and A. Angioni, "Nematicidal activity of (E,E)-2,4-Decadienal and (E)-2Decenal from ailanthus altissima against Meloidogyne javanica," Journal of Agricultural and Food Chemistry, vol. 60, no. 4, pp. 1146-1151, 2012.

[52] A. Zibaee and A. R. Bandani, "Effects of Artemisia annua L. (Asteracea) on the digestive enzymatic profiles and the cellular immune reactions of the Sunn pest, Eurygaster integriceps (Heteroptera: scutellaridae), against Beauveria bassiana," Bulletin of Entomological Research, vol. 100, no. 2, pp. 185-196, 2010.

[53] M. D. Moreira, M. C. Picanço, L. C. A. Barbosa, R. N. C. Guedes, E. C. Barros, and M. R. Campos, "Compounds fromAgeratum conyzoides: isolation, structural elucidation and insecticidal activity," Pest Management Science, vol. 63, no. 6, pp. 615-621, 2007.

[54] F. Mansour, H. Azaizeh, B. Saad, Y. Tadmor, F. Abo-Moch, and O. Said, "The potential of middle eastern flora as a source of new safe bio-acaricides to controlTetranychus cinnabarinus, the carmine spider mite," Phytoparasitica, vol. 32, no. 1, pp. 66-72, 2004.

[55] G. Valladares, M. T. Defago, S. Palacios, and M. C. Carpinella, "Laboratory evaluation of melia azedarach (meliaceae) extracts against the elm leaf beetle (Coleoptera: chrysomelidae)," Journal of Economic Entomology, vol. 90, no. 3, pp. 747-750, 1997.

[56] G. Rosell, C. Quero, J. Coll, and A. Guerrero, "Biorational insecticides in pest management," Journal of Pesticide Science, vol. 33, no. 2, pp. 103-121, 2008.

[57] J. Sun, Y. Guo, M. M. Scarlat, G. Lv, X. G. Yang, and Y. C. Hu, "Bibliometric study of the orthopaedic publications from China," International Orthopaedics, vol. 42, 2018.

[58] E. Hassan and A. Gökçe, "Production and consumption of biopesticides," in Advances in Plant Biopesticides, pp. 361-379, Springer, Berlin, Germany, 2014.

[59] P. Andreo-Martínez, V. M. Ortiz-Martínez, N. GarcíaMartínez et al., "A descriptive bibliometric study on bioavailability of pesticides in vegetables, food or wine research (1976-2018)," Environmental Toxicology and Pharmacology, vol. 77, 2020.

[60] E. T. Nyahangare, B. M. Mvumi, and T. Mutibvu, "Ethnoveterinary plants and practices used for ecto-parasite control in semi-arid smallholder farming areas of Zimbabwe," Journal of Ethnobiology and Ethnomedicine, vol. 11, pp. 1-16, 2015.

[61] S. Siamaki, E. Geraei, and F. Zare-Farashbandi, "A study on scientific collaboration and co-authorship patterns in library and information science studies in Iran between 2005 and 2009," Journal of Education and Health Promotion, vol. 3, p. 99, 2014.

[62] S. e. H. Zyoud, "Investigating global trends in paraquat intoxication research from 1962 to 2015 using bibliometric analysis," American Journal of Industrial Medicine, vol. 61, no. 6, pp. 462-470, 2018.

[63] S. Zyoud, W. Waring, S. Al-Jabi, and W. Sweileh, "Global research production in glyphosate intoxication from 1978 to 2015: a bibliometric analysis," Human \& Experimental Toxicology, vol. 36, no. 10, pp. 997-1006, 2017.

[64] T. V. Nguyen, T. P. Ho-Le, and U. V. Le, "International collaboration in scientific research in Vietnam: an analysis of patterns and impact," Scientometrics, vol. 110, no. 2, pp. 1035-1051, 2017.

[65] O. E. Sala, F. S. Chapin, J. J. Armesto et al., "Global biodiversity scenarios for the year 2100," Science, vol. 287, 2000.

[66] S. Williamson, "Understanding the full costs of pesticides: experience from the field, with a focus on Africa," in Pesticides-The Impacts of Pesticides ExposureInTech Open, London, UK, 2011.

[67] B. Dinham, "Growing vegetables in developing countries for local urban populations and export markets: problems confronting small-scale producers," Pest Management Science, vol. 59, no. 5, pp. 575-582, 2003. 